\title{
Fuzzy Stability of Generalized Mixed Type Cubic, Quadratic, and Additive Functional Equation
}

\author{
Madjid Eshaghi Gordji ${ }^{1}$, Mahdie Kamyarr ${ }^{1}$ Hamid Khodaei ${ }^{1}$, Dong Yun Shin ${ }^{2}$ and Choonkil Park ${ }^{3^{*}}$
}

\author{
* Correspondence: baak@hanyang. \\ ac.kr \\ ${ }^{3}$ Department of Mathematics, \\ Research Institute For Natural \\ Sciences, Hanyang University, Seoul \\ 133-791, Korea \\ Full list of author information is \\ available at the end of the article
}

\section{Abstract}

In this paper, we prove the generalized Hyers-Ulam stability of generalized mixed type cubic, quadratic, and additive functional equation, in fuzzy Banach spaces. 2010 Mathematics Subject Classification: 39B82; 39B52.

Keywords: fuzzy Hyers-Ulam stability, mixed functional equation, fuzzy normed space

\section{Introduction}

The stability problem of functional equations originated from a question of Ulam [1] concerning the stability of group homomorphisms. Hyers [2] gave a first affirmative answer to the question of Ulam for Banach spaces. Hyers' theorem was generalized by Aoki [3] for additive mappings and by Rassias [4] for linear mappings by considering an unbounded Cauchy difference. The paper of Rassias [4] has provided a lot of influence in the development of what we now call generalized Hyers-Ulam stability of functional equations. In 1994, a generalization of the Rassias' theorem was obtained by Găvruta [5] by replacing the unbounded Cauchy difference by a general control function in the spirit of Rassias' approach.

The functional equation

$$
f(x+y)+f(x-y)=2 f(x)+2 f(y)
$$

is related to a symmetric bi-additive mapping [6,7]. It is natural that this equation is called a quadratic functional equation. In particular, every solution of the quadratic equation (1.1) is said to be a quadratic mapping. It is well known that a mapping $f$ between real vector spaces is quadratic if and only if there exits a unique symmetric bi-additive mapping $B$ such that $f(x)=B(x, x)$ for all $x$ (see [6,7]). The bi-additive mapping $B$ is given by

$$
B(x, y)=\frac{1}{4}(f(x+y)-f(x-y))
$$

A generalized Hyers-Ulam stability problem for the quadratic functional equation (1.1) was proved by Skof for mappings $f: A \rightarrow B$, where $A$ is normed space and $B$ is a Banach space [8] (see [9-12]). 
Jun and Kim [13] introduced the following cubic functional equation

$$
f(2 x+y)+f(2 x-y)=2 f(x+y)+2 f(x-y)+12 f(x)
$$

and they established the general solution and the generalized Hyers-Ulam stability for the functional equation (1.3). They proved that a mapping $f$ between two real vector spaces $X$ and $Y$ is a solution of (1.3) if and only if there exists a unique mapping $C$ $: X \times X \times X \rightarrow Y$ such that $f(x)=C(x, x, x)$ for all $x \in X$, moreover, $C$ is symmetric for each fixed one variable and is additive for fixed two variables. The mapping $C$ is given by

$$
C(x, y, z)=\frac{1}{24}(f(x+y+z)+f(x-y-z)-f(x+y-z)-f(x-y+z))
$$

for all $x, y, z \in X$. During the last decades, several stability problems for various functional equations have been investigated by many mathematicians; [14-21].

Eshaghi and Khodaei [22] have established the general solution and investigated the generalized Hyers-Ulam stability for a mixed type of cubic, quadratic, and additive functional equation with $f(0)=0$,

$$
f(x+k y)+f(x-k y)=k^{2} f(x+y)+k^{2} f(x-y)+2\left(1-k^{2}\right) f(x)
$$

in quasi-Banach spaces, where $k$ is nonzero integer numbers with $k \neq \pm 1$. Obviously, the function $f(x)=a x+b x^{2}+c x^{3}$ is a solution of the functional equation (1.5). Interesting new results concerning mixed functional equations has recently been obtained by Najati et. al. $[23,24]$, Jun and Kim $[25,26]$ as well as for the fuzzy stability of a mixed type of additive and quadratic functional equation by Park [27] (see also [28-43]).

This paper is organized as follows: In Section 3, we prove the generalized HyersUlam stability of the functional equation (1.5) in fuzzy Banach spaces for an even case. In Section 4, we prove the generalized Hyers-Ulam stability of the functional equation (1.5) in fuzzy Banach spaces for an odd case. In Section 5, we prove the generalized Hyers-Ulam stability of generalized mixed cubic, quadratic, and additive functional equation (1.5) in fuzzy Banach spaces.

\section{Preliminaries}

We use the definition of fuzzy normed spaces given in [44] to investigate a fuzzy version of the generalized Hyers-Ulam stability for the functional equation (1.5) in the fuzzy normed space setting.

Definition 2.1. (Bag and Samanta [44], Mirmostafaee [45]). Let $X$ be a real linear space. A function $N: X \times \mathbb{R} \rightarrow[0,1]$ is said to be a fuzzy norm on $X$ if for all $x, y \in$ $X$ and all $s, t \in \mathbb{R}$;

$\left(N_{1}\right) N(x, t)=0$ for all $t \leq 0$;

$\left(N_{2}\right) x=0$ if and only if $N(x, t)=1$ for all $t>0$;

$\left(N_{3}\right) N(c x, t)=N\left(x, \frac{t}{|c|}\right)$ if $c \neq 0$;

$\left(N_{4}\right) N(x+y, s+t) \geq \min \{N(x, s), N(y, t)\}$

$\left(N_{5}\right) N(x, \cdot)$ is non-decreasing function on $\mathbb{R}$ and $\lim _{t \rightarrow \infty} N(x, t)=1$;

$\left(N_{6}\right) N(x, \cdot)$ is left continuous on $\mathbb{R}$ for every $x \neq 0$. 
The pair $(\mathrm{X}, \mathrm{N})$ is called a fuzzy normed linear space.

The properties of fuzzy normed vector spaces and examples of fuzzy norms are given in $([3,45-47])$.

Definition 2.2. (Bag and Samanta [44], Mirmostafaee [45]). Let $(X, N)$ be a fuzzy normed linear space. A sequence $\left\{x_{n}\right\}$ in $X$ is said to be convergent if there exists $x \in$ $X$ such that $\lim _{n \rightarrow \infty} N\left(x_{n}-x, t\right)=1$ for all $t>0$. In that case, $x$ is called the limit of the sequence $\left(x_{n}\right)$ and we write $N-\lim _{n \rightarrow \infty} x_{n}=x$.

Definition 2.3. (Bag and Samanta [44], Mirmostafaee [45]). Let $(X, N)$ be a fuzzy normed linear space. A sequence $\left\{x_{n}\right\}$ in $\mathrm{X}$ is called Cauchy if for each $\epsilon>0$ and each $\delta>0$, there exists $n_{0} \in \mathbb{N}$ such that $N\left(x_{m}-x_{n}, \delta\right)>1-\epsilon\left(m, n \geq n_{0}\right)$.

It is well known that every convergent sequence in a fuzzy normed vector space is Cauchy. If each Cauchy sequence is convergent, then the fuzzy norm is said to be complete and the fuzzy normed vector space is called a fuzzy Banach space.

We say that a function $f: X \rightarrow Y$ between fuzzy normed vector spaces $X$ and $Y$ is continuous at a point $x_{0} \in X$ if for each sequence $\left\{x_{k}\right\}$ converging to $x_{0}$ in $X$, then the sequence $\left\{f\left(x_{k}\right)\right\}$ converges to $f\left(x_{0}\right)$. If $f: X \rightarrow Y$ is continuous at each $x \in X$, then $f: X$ $\rightarrow Y$ is said to be continuous on $X$ (see [48]).

In the rest of this paper, unless otherwise explicitly stated, we will assume that $X$ is a vector space, $\left(Z, N^{\prime}\right)$ is a fuzzy normed space, and $(Y, N)$ is a fuzzy Banach space. For convenience, we use the following abbreviation for a given function $f: X \rightarrow Y$,

$$
D_{f}(x, y)=f(x+k y)+f(x-k y)-k^{2} f(x+y)-k^{2} f(x-y)-2\left(1-k^{2}\right) f(x)
$$

for all $x, y \in X$, where $k$ is nonzero integer numbers with $k \neq \pm 1$.

\section{Fuzzy stability of the functional equation (1.5): an even case}

In this section, we prove the generalized Hyers-Ulam stability of the functional equation (1.5) in fuzzy Banach spaces, for an even case. From now on, $V_{1}$ and $V_{2}$ will be real vector spaces.

Lemma 3.1. [22]. If an even mapping $f: V_{1} \rightarrow V_{2}$ satisfies (1.5), then $f(x)$ is quadratic.

Theorem 3.2. Let $\ell \in\{-1,1\}$ be fixed and let $\phi_{q}: X \times X \rightarrow Y$ be a mapping such that

$$
\varphi_{q}(k x, k y)=\alpha \varphi_{q}(x, y)
$$

for all $x, y \in X$ and for some positive real number $\alpha$ with $\alpha \ell<k^{2} \ell$. Suppose that an even mapping $f: X \rightarrow Y$ with $f(0)=0$ satisfies the inequality

$$
N\left(D_{f}(x, y), t\right) \geq N^{\prime}\left(\varphi_{q}(x, y), t\right)
$$

for all $x, y \in X$ and all $t>0$. Then, the limit

$$
\left.Q(x)=N-\lim _{n \rightarrow \infty} \frac{f\left(k^{\ell n} x\right)}{k^{2 \ell n}}\right)
$$

exists for all $x \in X$ and $Q: X \rightarrow Y$ is a unique quadratic mapping satisfying

$$
N(f(x)-Q(x), t) \geq N^{\prime}\left(\varphi_{q}(0, x), \frac{\ell\left(k^{2}-\alpha\right) t}{2}\right)
$$

for all $x \in X$ and all $t>0$. 
Proof. Case (1): $\ell=1$. By putting $x=0$ in (3.2) and then using evenness of $f$ and $f(0)$ $=0$, we obtain

$$
N\left(2 f(k y)-2 k^{2} f(y), t\right) \geq N^{\prime}\left(\varphi_{q}(0, y), t\right)
$$

for all $x, y \in X$ and all $t>0$. If we replace $y$ in (3.4) by $x$, we get

$$
N\left(f(k x)-k^{2} f(x), \frac{t}{2}\right) \geq N^{\prime}\left(\varphi_{q}(0, x), t\right)
$$

for all $x \in X$. So

$$
N\left(\frac{f(k x)}{k^{2}}-f(x), \frac{t}{2 k^{2}}\right) \geq N^{\prime}\left(\varphi_{q}(0, x), t\right)
$$

for all $x \in X$ and all $t>0$. Then by our assumption

$$
N^{\prime}\left(\varphi_{q}(0, k x), t\right)=N^{\prime}\left(\varphi_{q}(0, x), \frac{t}{\alpha}\right)
$$

for all $x \in X$ and all $t>0$. Replacing $x$ by $k^{n} x$ in (3.6) and using (3.7), we obtain

$$
N\left(\frac{f\left(k^{n+1} x\right)}{k^{2(n+1)}}-\frac{f\left(k^{n} x\right)}{k^{2 n}}, \frac{t}{k^{2}\left(k^{2 n}\right)}\right) \geq N^{\prime}\left(\varphi_{q}\left(0, k^{n} x\right), t\right)=N^{\prime}\left(\varphi_{q}(0, x), \frac{t}{\alpha^{n}}\right)
$$

for all $x \in X, t>0$ and $n \geq 0$. Replacing $t$ by $\alpha^{n} t$ in (3.8), we see that

$$
N\left(\frac{f\left(k^{n+1} x\right)}{k^{2(n+1)}}-\frac{f\left(k^{n} x\right)}{k^{2 n}}, \frac{\alpha^{n} t}{k^{2}\left(k^{2 n}\right)}\right) \geq N^{\prime}\left(\varphi_{q}(0, x), t\right)
$$

for all $x \in X, t>0$ and $n>0$. It follows from $\frac{f\left(k^{n} x\right)}{k^{2 n}}-f(x)=\sum_{j=0}^{n-1}\left(\frac{f\left(k^{j+1} x\right)}{k^{2(j+1)}}-\frac{f\left(k^{j} x\right)}{k^{2 j}}\right)$ and (3.9) that

$$
\begin{aligned}
N\left(\frac{f\left(k^{n} x\right)}{k^{2 n}}-f(x), \sum_{j=0}^{n-1} \frac{\alpha^{j} t}{k^{2}\left(k^{2}\right)^{j}}\right) & \geq \min \bigcup_{j=0}^{n-1}\left\{N\left(\frac{f\left(k^{j+1} x\right)}{k^{2(j+1)}}-\frac{f\left(k^{j} x\right)}{k^{2 j}}, \frac{\alpha^{j} t}{k^{2}\left(k^{2}\right)^{j}}\right)\right\} \\
& \geq N^{\prime}\left(\varphi_{q}(0, x), t\right)
\end{aligned}
$$

for all $x \in X, t>0$ and $n>0$. Replacing $x$ by $k^{m} x$ in (3.10), we observe that

$$
N\left(\frac{f\left(k^{n+m} x\right)}{k^{2(n+m)}}-\frac{f\left(k^{m} x\right)}{k^{2 m}}, \sum_{j=0}^{n-1} \frac{\alpha^{j} t}{k^{2}\left(k^{2}\right)^{j+m}}\right) \geq N^{\prime}\left(\varphi_{q}\left(0, k^{m} x\right), t\right)=N^{\prime}\left(\varphi(0, x), \frac{t}{\alpha^{m}}\right)
$$

for all $x \in X$, all $t>0$ and all $m \geq 0, n>0$. Hence

$$
N\left(\frac{f\left(k^{n+m} x\right)}{k^{2(n+m)}}-\frac{f\left(k^{m} x\right)}{k^{2 m}}, \sum_{j=m}^{n+m-1} \frac{\alpha^{j} t}{k^{2}\left(k^{2}\right)^{j}}\right) \geq N^{\prime}\left(\varphi_{q}(0, x), t\right)
$$

for all $x \in X$, all $t>0$ and all $m \geq 0, n>0$. By last inequality, we obtain

$$
N\left(\frac{f\left(k^{n+m} x\right)}{k^{2(n+m)}}-\frac{f\left(k^{m} x\right)}{k^{2 m}}, t\right) \geq N^{\prime}\left(\varphi_{q}(0, x), \frac{t}{\sum_{j=m}^{n+m-1} \frac{\alpha^{j}}{k^{2}\left(k^{2}\right)^{j}}}\right)
$$


for all $x \in X$, all $t>0$ and all $m \geq 0, n>0$. Since $0<\alpha<k^{2}$ and $\sum_{j=0}^{\infty}\left(\frac{\alpha}{k^{2}}\right)^{j}<\infty$, the Cauchy criterion for convergence and $\left(N_{5}\right)$ imply that $\left\{\frac{f\left(k^{n} x\right)}{k^{2 n}}\right\}$ is a Cauchy sequence in $Y$. Since $Y$ is a fuzzy Banach space, this sequence converges to some point $Q(x) \in Y$. So one can define the function $Q: X \rightarrow Y$ by

$$
\left.Q(x)=N-\lim _{n \rightarrow \infty} \frac{f\left(k^{n} x\right)}{k^{2 n}}\right)
$$

for all $x \in X$. Fix $x \in X$ and put $m=0$ in (3.11) to obtain

$$
N\left(\frac{f\left(k^{n} x\right)}{k^{2 n}}-f(x), t\right) \geq N^{\prime}\left(\varphi_{q}(0, x), \frac{t}{\sum_{j=0}^{n-1} \frac{\alpha^{j}}{k^{2}\left(k^{2}\right)^{j}}}\right)
$$

for all $x \in X$, all $t>0$ and all $n>0$. From which we obtain

$$
\begin{aligned}
N(Q(x)-f(x), t) & \geq \min \left\{N\left(Q(x)-\frac{f\left(k^{n} x\right)}{k^{2 n}}, \frac{t}{2}\right), N\left(\frac{f\left(k^{n} x\right)}{k^{2 n}}-f(x), \frac{t}{2}\right)\right\} \\
& \geq N^{\prime}\left(\varphi_{q}(0, x), \frac{t}{\sum_{j=0}^{n-1} \frac{2 \alpha^{j}}{k^{2}\left(k^{2}\right)^{j}}}\right)
\end{aligned}
$$

for $n$ large enough. Taking the limit as $n \rightarrow \infty$ in (3.13), we obtain

$$
N(Q(x)-f(x), t) \geq N^{\prime}\left(\varphi_{q}(0, x), \frac{\left(k^{2}-\alpha\right) t}{2}\right)
$$

for all $x \in X$ and all $t>0$. It follows from (3.8) and (3.12) that

$$
\begin{aligned}
N\left(\frac{Q(k x)}{k^{2}}-Q(x), t\right) \geq & \min \left\{N\left(\frac{Q(k x)}{k^{2}}-\frac{f\left(k^{n+1} x\right)}{k^{2(n+1)}}, \frac{t}{3}\right), N\left(\frac{f\left(k^{n} x\right)}{k^{2 n}}-Q(x), \frac{t}{3}\right),\right. \\
& \left.N\left(\frac{f\left(k^{n+1} x\right)}{k^{2(n+1)}}-\frac{f\left(k^{n} x\right)}{k^{2 n}}, \frac{t}{3}\right)\right\}=N^{\prime}\left(\varphi_{q}(0, x), \frac{k^{2}\left(k^{2 n}\right) t}{3 \alpha^{n}}\right)
\end{aligned}
$$

for all $x \in X$ and all $t>0$. Therefore,

$$
Q(k x)=k^{2} Q(x)
$$

for all $x \in X$. Replacing $x, y$ by $k^{n} x, k^{n} y$ in (3.2), respectively, we obtain

$$
N\left(\frac{1}{k^{2 n}} D_{f}\left(k^{n} x, k^{n} y\right), t\right) \geq N^{\prime}\left(\varphi_{q}\left(k^{n} x, k^{n} y\right), k^{2 n} t\right)=N^{\prime}\left(\varphi_{q}(x, y), \frac{k^{2 n} t}{\alpha^{n}}\right)
$$

which tends to 1 as $n \rightarrow \infty$ for all $x, y \in X$ and all $t>0$. So, we see that $Q$ satisfies (1.5). Thus, by Lemma 3.1, the function $x \rightsquigarrow f(x)$ is quadratic. Therefore, (3.15) implies that the function $Q$ is quadratic.

Now, to prove the uniqueness property of $Q$, let $Q^{\prime}: X \rightarrow Y$ be another quadratic function satisfying (3.3). It follows from (3.3), (3.7) and (3.15) that 


$$
\begin{aligned}
N\left(Q(x)-Q^{\prime}(x), t\right) & =N\left(\frac{Q\left(k^{n} x\right)}{k^{2 n}}-\frac{Q^{\prime}\left(k^{n} x\right)}{k^{2 n}}, t\right) \\
& \geq \min \left\{N\left(\frac{Q\left(k^{n} x\right)}{k^{2 n}}-\frac{f\left(k^{n} x\right)}{k^{2 n}}, \frac{t}{2}\right), N\left(\frac{f\left(k^{n} x\right)}{k^{2 n}}-\frac{Q^{\prime}\left(k^{n} x\right)}{k^{2 n}}, \frac{t}{2}\right)\right\} \\
& \geq N^{\prime}\left(\varphi_{q}\left(0, k^{n} x\right), \frac{k^{2 n}\left(k^{2}-\alpha\right) t}{4}\right)=N^{\prime}\left(\varphi_{q}(0, x), \frac{k^{2 n}\left(k^{2}-\alpha\right) t}{4 \alpha^{n}}\right)
\end{aligned}
$$

for all $x \in X$ and all $t>0$. Since $\alpha<k^{2}$, we obtain $\lim _{n \rightarrow \infty} N^{\prime}\left(\varphi_{q}(0, x), \frac{k^{2 n}\left(k^{2}-\alpha\right) t}{4 \alpha^{n}}\right)=1$. Thus, $Q(x)=Q^{\prime}(x)$.

Case (2): $\ell=-1$. We can state the proof in the same pattern as we did in the first case.

Replacing $x$ by $\frac{x}{k}$ in (3.5), we obtain

$$
N\left(f(x)-k^{2} f\left(\frac{x}{k}\right), \frac{t}{2}\right) \geq N^{\prime}\left(\varphi_{q}\left(0, \frac{x}{k}\right), t\right)
$$

for all $x \in X$ and all $t>0$. Replacing $x$ and $t$ by $\frac{x}{k^{n}}$ and $\frac{t}{k^{2 n}}$ in (3.16), respectively, we obtain

$$
N\left(k^{2 n} f\left(\frac{x}{k^{n}}\right)-k^{2(n+1)} f\left(\frac{x}{k^{n+1}}\right), \frac{t}{2}\right) \geq N^{\prime}\left(\varphi_{q}\left(0, \frac{x}{k^{n+1}}\right), \frac{t}{k^{2 n}}\right)=N^{\prime}\left(\varphi_{q}(0, x),\left(\frac{\alpha}{k^{2}}\right)^{n} \alpha t\right)
$$

for all $x \in X$, all $t>0$ and all $n>0$. One can deduce

$$
N\left(k^{2(n+m)} f\left(\frac{x}{k^{n+m}}\right)-k^{2 m} f\left(\frac{x}{k^{m}}\right), t\right) \geq N^{\prime}\left(\varphi_{q}(0, x), \frac{t}{\sum_{j=m+1}^{n+m} \frac{2 k^{2 j}}{k^{2} \alpha^{j}}}\right)
$$

for all $x \in X$, all $t>0$ and all $m \geq 0, n \geq 0$. From which we conclude that $\left\{k^{2 n} f\left(\frac{x}{k^{n}}\right)\right\}$ is a Cauchy sequence in the fuzzy Banach space $(Y, N)$. Therefore, there is a mapping $Q: X \rightarrow Y$ defined by $Q(x):=N-\lim _{n \rightarrow \infty} k^{2 n} f\left(\frac{x}{k^{n}}\right)$. Employing (3.17) with $m=0$, we obtain

$$
N(Q(x)-f(x), t) \geq N^{\prime}\left(\varphi_{q}(0, x), \frac{\left(\alpha-k^{2}\right) t}{2}\right)
$$

for all $x \in X$ and all $t>0$. The proof for uniqueness of $Q$ for this case proceeds similarly to that in the previous case, hence it is omitted.

Remark 3.3. Let $0<\alpha<k^{2}$. Suppose that the function $t \mapsto N(f(x)-Q(x)$, .) from $(0, \infty)$ into $[0,1]$ is right continuous. Then, we obtain a better fuzzy (3.14) as follows.

We obtain

$$
\begin{aligned}
N(Q(x)-f(x), t+s) & \geq \min \left\{N\left(Q(x)-\frac{f\left(k^{n} x\right)}{k^{2 n}}, s\right), N\left(\frac{f\left(k^{n} x\right)}{k^{2 n}}-f(x), t\right)\right\} \\
& \geq N^{\prime}\left(\varphi_{q}(0, x), \frac{t}{\left.\sum_{j=0}^{n-1} \frac{\alpha^{j}}{k^{2}(k)^{2 j}}\right)}\right) \\
& \geq N^{\prime}\left(\varphi_{q}(0, x),\left(k^{2}-\alpha\right) t\right) .
\end{aligned}
$$


Tending $s$ to zero we infer that

$$
N(Q(x)-f(x), t) \geq N^{\prime}\left(\varphi_{q}(0, x),\left(k^{2}-\alpha\right) t\right)
$$

for all $x \in X$ and all $t>0$.

From Theorem 3.2, we obtain the following corollary concerning the generalized Hyers-Ulam stability [4] of quadratic mappings satisfying (1.5), in normed spaces.

Corollary 3.4. Let $X$ be a normed space and $Y$ be a Banach space. Let $\varepsilon, \lambda$ be nonnegative real numbers such that $\lambda \neq 2$. Suppose that an even mapping $f: X \rightarrow Y$ with $f$ (0) $=0$ satisfies

$$
\left\|D_{f}(x, y)\right\| \leq \varepsilon\left(\|x\|^{\lambda}+\|y\|^{\lambda}\right)
$$

for all $x, y \in X$. Then, the limit

$$
\left.Q(x)=N-\lim _{n \rightarrow \infty} \frac{f\left(k^{\ell n} x\right)}{k^{2 \ell n}}\right)
$$

exists for all $x \in X$ and $Q: X \rightarrow Y$ is a unique quadratic mapping satisfying

$$
\|f(x)-Q(x)\| \leq \frac{2 \varepsilon\|x\|^{\lambda}}{\ell\left(k^{2}-k^{\lambda}\right)}
$$

for all $x \in X$, where $\lambda \ell<2 \ell$.

Proof. Define the function $N$ by

$$
N(x, t)= \begin{cases}\frac{t}{t+\|x\|}, & t>0 \\ 0, & t \leq 0\end{cases}
$$

It is easy to see that $(X, N)$ is a fuzzy normed space and $(Y, N)$ is a fuzzy Banach space. Denote $\phi_{q}: X \times X \rightarrow \mathbb{R}$, the function sending each $(x, y)$ to $\varepsilon\left(\|x\|\left\|^{\lambda}+\right\| y \|^{\lambda}\right)$. By assumption

$$
N\left(D_{f}(x, y), t\right) \geq N^{\prime}\left(\varphi_{q}(x, y), t\right)
$$

note that $N^{\prime}: \mathbb{R} \times \mathbb{R} \rightarrow[0,1]$ given by

$$
N^{\prime}(x, t)= \begin{cases}\frac{t}{t+|x|}, & t>0 \\ 0, & t \leq 0\end{cases}
$$

is a fuzzy norm on $\mathbb{R}$. By Theorem 3.2, there exists a unique quadratic mapping $Q$ : $X \rightarrow Y$ satisfying the equation (1.5) and

$$
\begin{aligned}
\frac{t}{t+\|f(x)-Q(x)\|} & =N(f(x)-Q(x), t) \\
& \geq N^{\prime}\left(\varphi_{q}(0, x), \frac{\ell\left(k^{2}-k^{\lambda}\right) t}{2}\right) \\
& =N^{\prime}\left(\varepsilon\|x\|^{\lambda}, \frac{\ell\left(k^{2}-k^{\lambda}\right) t}{2}\right)=\frac{\ell\left(k^{2}-k^{\lambda}\right) t}{\ell\left(k^{2}-k^{\lambda}\right) t+2 \varepsilon\|x\|^{\lambda}}
\end{aligned}
$$

and thus

$$
\frac{t}{t+\|f(x)-Q(x)\|} \geq \frac{\ell\left(k^{2}-k^{\lambda}\right) t}{\ell\left(k^{2}-k^{\lambda}\right) t+2 \varepsilon\|x\|^{\lambda}}
$$

which implies that, $\ell\left(k^{2}-k^{\lambda}\right)\|f(x)-Q(x)\| \leq 2 \varepsilon\|x\|^{\lambda}$ for all $x \in X$. 
In the following theorem, we will show that under some extra conditions on Theorem 3.2, the quadratic function $r \mapsto Q(r x)$ is fuzzy continuous. It follows that in such a case, $Q(r x)=r^{2} Q(x)$ for all $x \in X$ and $r \in \mathbb{R}$.

In the following result, we will assume that all conditions of the theorem 3.2 hold.

Theorem 3.5. Denote $N_{1}$ the fuzzy norm obtained as Corollary 3.4 on $\mathbb{R}$. Let for all $x$ $\in X$, the functions $r \mapsto f(r x)$ (from $\left(\mathbb{R}, N_{1}\right)$ into $(Y, N)$ ) and $r \mapsto \phi_{q}(0, r x)$ (from $\left(\mathbb{R}, N_{1}\right)$ into $\left.\left(Z, N^{\prime}\right)\right)$ be fuzzy continuous. Then, for all $x \in X$, the function $r \mapsto Q(r x)$ is fuzzy continuous and $Q(r x)=r^{2} Q(x)$ for all $r \in \mathbb{R}$.

Proof. Case (1): $\ell=1$. Let $\left\{r_{k}\right\}$ be a sequence in $\mathbb{R}$ that converge to some $r \in \mathbb{R}$, and let $t>0$. Let $\varepsilon>0$ be given, since $0<\alpha<k^{2}$, so $\lim _{n \rightarrow \infty} \frac{\left(k^{2}-\alpha\right) k^{2 n} t}{12 \alpha^{n}}=\infty$, there is $m \in \mathbb{N}$ such that

$$
N^{\prime}\left(\varphi_{q}(0, r x), \frac{\left(k^{2}-\alpha\right) k^{2 m} t}{12 \alpha^{m}}\right)>1-\varepsilon
$$

It follows from (3.14) and (3.20) that

$$
N\left(\frac{f\left(k^{m} r x\right)}{k^{2 m}}-\frac{Q\left(k^{m} r x\right)}{k^{2 m}}, \frac{t}{3}\right)>1-\varepsilon
$$

By the fuzzy continuity of functions $r \mapsto f(r x)$ and $r \mapsto \phi_{q}(0, r x)$, we can find some $\mathcal{J} \in \mathbb{N}$ such that for any $n \geq j$,

$$
N\left(\frac{f\left(k^{m} r_{k} x\right)}{k^{2 m}}-\frac{f\left(k^{m} r x\right)}{k^{2 m}}, \frac{t}{3}\right)>1-\varepsilon
$$

and

$$
N^{\prime}\left(\varphi_{q}\left(0, r_{k} x\right)-\varphi_{q}(0, r x), \frac{\left(k^{2}-\alpha\right) k^{2 m} t}{12 \alpha^{m}}\right)>1-\varepsilon
$$

It follows from (3.20) and (3.23) that

$$
N^{\prime}\left(\varphi_{q}\left(0, r_{k} x\right), \frac{\left(k^{2}-\alpha\right) k^{2 m} t}{6 \alpha^{m}}\right)>1-\varepsilon
$$

On the other hand,

$$
\begin{aligned}
N\left(Q\left(r_{k} x\right)-\frac{f\left(k^{m} r_{k} x\right)}{k^{2 m}}, \frac{t}{k^{2 m}}\right) & =N\left(\frac{Q\left(k^{m} r_{k} x\right)}{k^{2 m}}-\frac{f\left(k^{m} r_{k} x\right)}{k^{2 m}}, \frac{t}{k^{2 m}}\right) \\
& \geq N^{\prime}\left(\varphi_{q}\left(0, r_{k} x\right), \frac{\left(k^{2}-\alpha\right) t}{2 \alpha^{m}}\right)
\end{aligned}
$$

It follows from (3.24) and (3.25) that

$$
N\left(Q\left(r_{k} x\right)-\frac{f\left(k^{m} r_{k} x\right)}{k^{2 m}}, \frac{t}{3}\right)>1-\varepsilon
$$

So, it follows from (3.21), (3.22) and (3.26) that for any $n \geq j$,

$$
N\left(Q\left(r_{k} x\right)-Q(r x), t\right)>1-\varepsilon
$$

Therefore, for every choice $x \in X, t>0$, and $\varepsilon>0$, we can find some $\mathcal{J} \in \mathbb{N}$ such that $N\left(Q\left(r_{k} x\right)-Q(r x), t\right)>1-\varepsilon$ for every $n \geq \mathcal{J}$. This shows that $Q\left(r_{k} x\right) \rightarrow Q(r x)$. The proof for $\ell=-1$ proceeds similarly to that in the previous case. 
It is not hard to see that $Q(r x)=r^{2} Q(x)$ for each rational number $r$. Since $Q$ is a fuzzy continuous function, by the same reasoning as in the proof of [45], the quadratic mapping $Q: X \rightarrow Y$ satisfies $Q(r x)=r^{2} Q(x)$ for each $r \in \mathbb{R}$.

\section{Fuzzy stability of the functional equation (1.5): an odd case}

In this section, we prove the generalized Hyers-Ulam stability of the functional equation (1.5) in fuzzy Banach spaces for an odd case.

Lemma 4.1. [22,24]. If an odd mapping $f: V_{1} \rightarrow V_{2}$ satisfies (1.5), then the mapping $g: V_{1} \rightarrow V_{2}$, defined by $g(x)=f(2 x)-8 f(x)$, is additive.

Theorem 4.2. Let $\ell \in\{-1,1\}$ be fixed and let $\phi_{q}: X \times X \rightarrow Z$ be a function such that

$$
\varphi_{a}(2 x, 2 y)=\alpha \varphi_{a}(x, y)
$$

for all $x, y \in X$ and for some positive real number $\alpha$ with $\alpha \ell<2 \ell$. Suppose that an odd mapping $f: X \rightarrow Y$ satisfies the inequality

$$
N\left(D_{f}(x, y), t\right) \geq N^{\prime}\left(\varphi_{a}(x, y), t\right)
$$

for all $x, y \in X$ and all $t>0$. Then, the limit

$$
A(x)=N-\lim _{n \rightarrow \infty} \frac{1}{2^{\ell n}}\left(f\left(2^{\ell n+1} x\right)-8 f\left(2^{\ell n} x\right)\right)
$$

exists for all $x \in X$ and $A: X \rightarrow Y$ is a unique additive mapping satisfying

$$
N(f(2 x)-8 f(x)-A(x), t) \geq M_{a}\left(x, \frac{\ell(2-\alpha)}{2} t\right)
$$

for all $x \in X$ and all $t>0$, where

$$
\begin{aligned}
M_{a}(x, t)=\min & \left\{N^{\prime}\left(\varphi_{a}(x, x), \frac{k^{2}\left(k^{2}-1\right)}{9 k^{2}+4} t\right), N^{\prime}\left(\varphi_{a}(2 x, x), \frac{k^{2}\left(k^{2}-1\right)}{9 k^{2}+4} t\right),\right. \\
& N^{\prime}\left(\varphi_{a}(x, 2 x), \frac{k^{2}\left(k^{2}-1\right)}{9 k^{2}+4} t\right), N^{\prime}\left(\varphi_{a}((k+1) x, x), \frac{k^{2}\left(k^{2}-1\right)}{9 k^{2}+4} t\right), \\
& \left.N^{\prime}\left(\varphi_{a}((k-1) x, x), \frac{k^{2}\left(k^{2}-1\right)}{9 k^{2}+4} t\right)\right), N^{\prime}\left(\varphi_{a}(2 x, 2 x), \frac{k^{2}\left(k^{2}-1\right)}{9 k^{2}+4} t\right), \\
& N^{\prime}\left(\varphi_{a}(x, 3 x), \frac{k^{2}\left(k^{2}-1\right)}{9 k^{2}+4} t\right), N^{\prime}\left(\varphi_{a}((2 k+1) x, x), \frac{k^{2}\left(k^{2}-1\right)}{9 k^{2}+4} t\right), \\
& \left.N^{\prime}\left(\varphi_{a}((2 k-1) x, x), \frac{k^{2}\left(k^{2}-1\right)}{9 k^{2}+4} t\right)\right\} .
\end{aligned}
$$

Proof. Case (1): $\ell=1$. It follows from (4.2) and using oddness of $f$ that

$$
\begin{aligned}
& N\left(f(k y+x)-f(k y-x)-k^{2} f(x+y)-k^{2} f(x-y)+2\left(k^{2}-1\right) f(x), t\right) \\
& \quad \geq N^{\prime}\left(\varphi_{a}(x, y), t\right)
\end{aligned}
$$

for all $x, y \in X$ and all $t>0$. Putting $y=x$ in (4.4), we have

$$
N\left(f((k+1) x)-f((k-1) x)-k^{2} f(2 x)+2\left(k^{2}-1\right) f(x), t\right) \geq N^{\prime}\left(\varphi_{a}(x, x), t\right)
$$

for all $x \in X$ and all $t>0$. It follows from (4.5) that

$$
N\left(f(2(k+1) x)-f(2(k-1) x)-k^{2} f(4 x)+2\left(k^{2}-1\right) f(2 x), t\right) \geq N^{\prime}\left(\varphi_{a}(2 x, 2 x), t\right)
$$


for all $x \in X$ and all $t>0$. Replacing $x$ and $y$ by $2 x$ and $x$ in (4.4), respectively, we get

$$
\begin{aligned}
& N\left(f((k+2) x)-f((k-2) x)-k^{2} f(3 x)-k^{2} f(x)+2\left(k^{2}-1\right) f(2 x), t\right) \\
& \quad \geq N^{\prime}\left(\varphi_{a}(2 x, x), t\right)
\end{aligned}
$$

for all $x \in X$. Setting $y=2 x$ in (4.4), we have

$$
\begin{aligned}
& N\left(f((2 k+1) x)-f((2 k-1) x)-k^{2} f(3 x)-k^{2} f(-x)+2\left(k^{2}-1\right) f(x), t\right) \\
& \quad \geq N^{\prime}\left(\varphi_{a}(x, 2 x), t\right)
\end{aligned}
$$

for all $x \in X$ and all $t>0$. Putting $y=3 x$ in (4.4), we obtain

$$
\begin{aligned}
& N\left(f((3 k+1) x)-f((3 k-1) x)-k^{2} f(4 x)-k^{2} f(-2 x)+2\left(k^{2}-1\right) f(x), t\right) \\
& \quad \geq N^{\prime}\left(\varphi_{a}(x, 3 x), t\right)
\end{aligned}
$$

for all $x \in X$ and all $t>0$. Replacing $x$ and $y$ by $(k+1) x$ and $x$ in (4.4), respectively, we get

$$
\begin{aligned}
& N\left(f((2 k+1) x)-f(-x)-k^{2} f((k+2) x)-k^{2} f(k x)+2\left(k^{2}-1\right) f((k+1) x), t\right) \\
& \quad \geq N^{\prime}\left(\varphi_{a}((k+1) x, x), t\right)
\end{aligned}
$$

for all $x \in X$ and all $t>0$. Replacing $x$ and $y$ by $(k-1) x$ and $x$ in (4.4), respectively, one gets

$$
\begin{aligned}
& N\left(f((2 k-1) x)-f(x)-k^{2} f((k-2) x)-k^{2} f(k x)+2\left(k^{2}-1\right) f((k-1) x), t\right) \\
& \quad \geq N^{\prime}\left(\varphi_{a}((k-1) x, x), t\right)
\end{aligned}
$$

for all $x \in X$ and all $t>0$. Replacing $x$ and $y$ by $(2 k+1) x$ and $x$ in (4.4), respectively, we obtain

$$
\begin{aligned}
& N\left(f((3 k+1) x)-f(-(k+1) x)-k^{2} f(2(k+1) x)-k^{2} f(2 k x)\right. \\
& \left.\quad+2\left(k^{2}-1\right) f((2 k+1) x), t\right) \geq N^{\prime}\left(\varphi_{a}((2 k+1) x, x), t\right)
\end{aligned}
$$

for all $x \in X$ and all $t>0$. Replacing $x$ and $y$ by $(2 k-1) x$ and $x$ in (4.4), respectively, we have

$$
\begin{aligned}
& N\left(f((3 k-1) x)-f(-(k-1) x)-k^{2} f(2(k-1) x)-k^{2} f(2 k x)\right. \\
& \left.\quad+2\left(k^{2}-1\right) f((2 k-1) x), t\right) \geq N^{\prime}\left(\varphi_{a}((2 k-1) x, x), t\right)
\end{aligned}
$$

for all $x \in X$ and all $t>0$. It follows from (4.5), (4.7), (4.8), (4.10) and (4.11) that

$$
\begin{aligned}
N & \left(2 f(3 x)-8 f(2 x)+10 f(x), \frac{2}{k^{2}\left(k^{2}-1\right)}\left(2\left(k^{2}-1\right)+k^{2}+3\right) t\right) \\
\geq & \min \left\{N^{\prime}\left(\varphi_{a}(x, x), t\right), N^{\prime}\left(\varphi_{a}(2 x, x), t\right), N^{\prime}\left(\varphi_{a}(x, 2 x), t\right),\right. \\
& \left.N^{\prime}\left(\varphi_{a}((k+1) x, x), t\right), N^{\prime}\left(\varphi_{a}((k-1) x, x), t\right)\right\}
\end{aligned}
$$

for all $x \in X$ and all $t>0$. And, from (4.5), (4.6), (4.8), (4.9), (4.12) and (4.14), we conclude that

$$
\begin{aligned}
N & \left(f(4 x)-2 f(3 x)-2 f(2 x)+6 f(x), \frac{1}{k^{2}\left(k^{2}-1\right)}\left(2\left(k^{2}-1\right)+k^{2}+4\right) t\right) \\
\geq & \min \left\{N^{\prime}\left(\varphi_{a}(x, x), t\right), N^{\prime}\left(\varphi_{a}(2 x, 2 x), t\right), N^{\prime}\left(\varphi_{a}(x, 2 x), t\right), N^{\prime}\left(\varphi_{a}(x, 3 x), t\right),\right. \\
& \left.N^{\prime}\left(\varphi_{a}((2 k+1) x, x), t\right), N^{\prime}\left(\varphi_{a}((2 k-1) x, x), t\right)\right\}
\end{aligned}
$$


for all $x \in X$ and all $t>0$. Finally, by using (4.14) and (4.15), we obtain that Similar to the proof Theorem 3.2, we have

$$
\begin{aligned}
& N\left(f(4 x)-10 f(2 x)+16 f(x), \frac{9 k^{2}+4}{k^{2}\left(k^{2}-1\right)} t\right) \geq \min \left\{N^{\prime}\left(\varphi_{a}(x, x), t\right), N^{\prime}\left(\varphi_{a}(2 x, x), t\right),\right. \\
& \left.N^{\prime}\left(\varphi_{a}(x, 2 x), t\right), N^{\prime}\left(\varphi_{a}((k+1) x, x), t\right), N^{\prime}\left(\varphi_{a}((k-1) x, x), t\right)\right), N^{\prime}\left(\varphi_{a}(2 x, 2 x), t\right), \\
& \left.N^{\prime}\left(\varphi_{a}(x, 3 x), t\right), N^{\prime}\left(\varphi_{a}((2 k+1) x, x), t\right), N^{\prime}\left(\varphi_{a}((2 k-1) x, x), t\right)\right\}
\end{aligned}
$$

for all $x \in X$ and all $t>0$, where

$$
\begin{aligned}
M_{a}(x, t)= & \min \left\{N^{\prime}\left(\varphi_{a}(x, x), \frac{k^{2}\left(k^{2}-1\right)}{9 k^{2}+4} t\right), N^{\prime}\left(\varphi_{a}(2 x, x), \frac{k^{2}\left(k^{2}-1\right)}{9 k^{2}+4} t\right),\right. \\
& N^{\prime}\left(\varphi_{a}(x, 2 x), \frac{k^{2}\left(k^{2}-1\right)}{9 k^{2}+4} t\right), N^{\prime}\left(\varphi_{a}((k+1) x, x), \frac{k^{2}\left(k^{2}-1\right)}{9 k^{2}+4} t\right), \\
& \left.N^{\prime}\left(\varphi_{a}((k-1) x, x), \frac{k^{2}\left(k^{2}-1\right)}{9 k^{2}+4} t\right)\right), N^{\prime}\left(\varphi_{a}(2 x, 2 x), \frac{k^{2}\left(k^{2}-1\right)}{9 k^{2}+4} t\right), \\
& N^{\prime}\left(\varphi_{a}(x, 3 x), \frac{k^{2}\left(k^{2}-1\right)}{9 k^{2}+4} t\right), N^{\prime}\left(\varphi_{a}((2 k+1) x, x), \frac{k^{2}\left(k^{2}-1\right)}{9 k^{2}+4} t\right), \\
& \left.N^{\prime}\left(\varphi_{a}((2 k-1) x, x), \frac{k^{2}\left(k^{2}-1\right)}{9 k^{2}+4} t\right)\right\}
\end{aligned}
$$

for all $x \in X$ and all $t>0$. Thus, (4.16) means that

$$
N(f(4 x)-10 f(2 x)+16 f(x), t) \geq M_{a}(x, t)
$$

for all $x \in X$ and all $t>0$. Let $g: X \rightarrow Y$ be a mapping defined by $g(x):=f(2 x)-8 f(x)$ for all $x \in X$. From (4.17), we conclude that

$$
N(g(2 x)-2 g(x), t) \geq M_{a}(x, t)
$$

for all $x \in X$ and all $t>0$. So

$$
N\left(\frac{g(2 x)}{2}-g(x), \frac{t}{2}\right) \geq M_{a}(x, t)
$$

for all $x \in X$ and all $t>0$. Then, by our assumption

$$
M_{a}(2 x, t)=M_{a}\left(x, \frac{t}{\alpha}\right)
$$

for all $x \in X$ and all $t>0$. Replacing $x$ by $2^{n} x$ in (4.19) and using (4.20), we obtain

$$
N\left(\frac{g\left(2^{n+1} x\right)}{2^{n+1}}-\frac{g\left(2^{n} x\right)}{2^{n}}, \frac{t}{2\left(2^{n}\right)}\right) \geq M_{a}\left(2^{n} x, t\right)=M_{a}\left(x, \frac{t}{\alpha^{n}}\right)
$$

for all $x \in X, t>0$ and $n \geq 0$. Replacing t by $\alpha^{n} t$ in (4.21), we see that

$$
N\left(\frac{g\left(2^{n+1} x\right)}{2^{n+1}}-\frac{g\left(2^{n} x\right)}{2^{n}}, \frac{t \alpha^{n}}{2\left(2^{n}\right)}\right) \geq M_{a}(x, t)
$$

for all $x \in X, t>0$ and $n>0$. It follows from $\frac{g\left(2^{n} x\right)}{2^{n}}-g(x)=\sum_{j=0}^{n-1}\left(\frac{g\left(2^{j+1} x\right)}{2^{j+1}}-\frac{g\left(2^{j} x\right)}{2^{j}}\right)$ and (4.22) that 


$$
\begin{aligned}
N\left(\frac{g\left(2^{n} x\right)}{2^{n}}-g(x), \sum_{j=0}^{n-1} \frac{\alpha^{j} t}{2(2)^{j}}\right) & \geq \min \bigcup_{j=0}^{n-1}\left\{N\left(\frac{g\left(2^{j+1} x\right)}{2^{j+1}}-\frac{g\left(2^{j} x\right)}{2^{j}}, \frac{\alpha^{j} t}{2(2)^{j}}\right)\right\} \\
& \geq M_{a}(x, t)
\end{aligned}
$$

for all $x \in X, t>0$ and $n>0$. Replacing $x$ by $2^{m} x$ in (4.23), we observe that

$$
N\left(\frac{g\left(2^{n+m} x\right)}{2^{n+m}}-\frac{g\left(2^{m} x\right)}{2^{m}}, \sum_{j=0}^{n-1} \frac{\alpha^{j} t}{2(2)^{j+m}}\right) \geq M_{a}\left(2^{m} x, t\right)=M_{a}\left(x, \frac{t}{\alpha^{m}}\right)
$$

for all $x \in X$, all $t>0$ and all $m \geq 0, n>0$. So

$$
N\left(\frac{g\left(2^{n+m} x\right)}{2^{n+m}}-\frac{g\left(2^{m} x\right)}{2^{m}}, \sum_{j=m}^{n+m-1} \frac{\alpha^{j} t}{2(2)^{j}}\right) \geq M_{a}(x, t)
$$

for all $x \in X$, all $t>0$ and all $m \geq 0, n>0$. Hence

$$
N\left(\frac{g\left(2^{n+m} x\right)}{2^{n+m}}-\frac{g\left(2^{m} x\right)}{2^{m}}, t\right) \geq M_{a}\left(x, \frac{t}{\sum_{j=m}^{n+m-1} \frac{\alpha^{j}}{2(2)^{j}}}\right)
$$

for all $x \in X$, all $t>0$ and all $m \geq 0, n>0$. Since $0<\alpha<2$ and $\sum_{n=0}^{\infty}\left(\frac{\alpha}{2}\right)^{n}<\infty$, the Cauchy criterion for convergence and $\left(N_{5}\right)$ imply that $\left\{\frac{g\left(2^{n} x\right)}{2^{n}}\right\}$ is a Cauchy sequence in $(Y, N)$ to some point $A(x) \in Y$. So one can define the mapping $A: X \rightarrow Y$ by

$$
\left.A(x)=N-\lim _{n \rightarrow \infty} \frac{g\left(2^{n} x\right)}{2^{n}}\right)
$$

for all $x \in X$. Fix $x \in X$ and put $m=0$ in (4.24) to obtain

$$
N\left(\frac{g\left(2^{n} x\right)}{2^{n}}-g(x), t\right) \geq M_{a}\left(x, \frac{t}{\sum_{j=0}^{n-1} \frac{\alpha^{j}}{2(2)^{j}}}\right)
$$

for all $x \in X, t>0$ and $n>0$. From which we obtain

$$
\begin{aligned}
N(A(x)-g(x), t) & \geq \min \left\{N\left(A(x)-\frac{g\left(2^{n} x\right)}{2^{n}}, \frac{t}{2}\right), N\left(\frac{g\left(2^{n} x\right)}{2^{n}}-g(x), \frac{t}{2}\right)\right\} \\
& \geq M_{a}\left(x, \frac{t}{\sum_{j=0}^{n-1} \frac{\alpha^{j}}{2 j}}\right)
\end{aligned}
$$

for $n$ large enough. Taking the limit as $n \rightarrow \infty$ in (4.26), we obtain

$$
N(A(x)-g(x), t) \geq M_{a}\left(x, \frac{t(2-\alpha)}{2}\right)
$$


for all $x \in X$ and all $t>0$. It follows from (4.21) and (4.25) that

$$
\begin{aligned}
N\left(\frac{A(2 x)}{2}-A(x), t\right) \geq & \min \left\{N\left(\frac{A(2 x)}{2}-\frac{g\left(2^{n+1} x\right)}{2^{n+1}}\right), \frac{t}{3}\right), N\left(\frac{g\left(2^{n} x\right)}{2^{n}}-A(x), \frac{t}{3}\right) \\
& \left., N\left(\frac{g\left(2^{n+1} x\right)}{2^{n+1}}-\frac{g\left(2^{n} x\right)}{2^{n}}\right), \frac{t}{3}\right)=M_{a}\left(x, \frac{2(2)^{n} t}{3 \alpha^{n}}\right)
\end{aligned}
$$

for all $x \in X$ and all $t>0$. Therefore,

$$
A(2 x)=2 A(x)
$$

for all $x \in X$. Replacing $x, y$ by $2^{n} x, 2^{n} y$ in (4.2), respectively, we obtain

$$
\begin{aligned}
N\left(\frac{1}{2^{n}} D_{g}\left(2^{n} x, 2^{n} y\right), t\right) & =N\left(D_{f}\left(2^{n+1} x, 2^{n+1} y\right)-8 D_{f}\left(2^{n} x, 2^{n} y\right), 2^{n} t\right) \\
& =\min \left\{N\left(D_{f}\left(2^{n+1} x, 2^{n+1} y\right), \frac{2^{n} t}{2}\right), N\left(D_{f}\left(2^{n} x, 2^{n} y\right), \frac{2^{n} t}{16}\right)\right\} \\
& \geq \min \left\{N^{\prime}\left(\varphi_{a}\left(2^{n+1} x, 2^{n+1} y\right), \frac{2^{n} t}{2}\right), N^{\prime}\left(\varphi_{a}\left(2^{n} x, 2^{n} y\right), \frac{2^{n} t}{16}\right)\right\} \\
& =\min \left\{N^{\prime}\left(\varphi_{a}(x, y), \frac{2^{n} t}{2 \alpha^{n+1}}\right), N^{\prime}\left(\varphi_{a}(x, y), \frac{2^{n} t}{16 \alpha^{n}}\right)\right\}
\end{aligned}
$$

which tends to 1 as $\mathrm{n} \rightarrow \infty$ for all $x, y \in X$ and all $t>0$. So we see that $A$ satisfies (1.5). Thus, by Lemma 4.1, the mapping $x \leadsto A(2 x)-8 A(x)$ is additive. So (4.28) implies that the mapping $A$ is additive.

The rest of the proof is similar to the proof of Theorem 3.2 and we omit the details.

Remark 4.3. Let $0<\alpha<2$. Suppose that the function $t \mapsto N(f(2 x)-8 f(x)-A(x)$, .) from $(0, \infty)$ into $[0,1]$ is right continuous. Then, we obtain a better fuzzy approximation than (4.27).

Corollary 4.4. Let $X$ be a normed space and $Y$ be a Banach space. Let $\varepsilon, \lambda$ be nonnegative real numbers such that $\lambda \neq 1$. Suppose that an odd mapping $f: X \rightarrow Y$ satisfies the inequality (3.18) for all $x, y \in X$. Then, the limit

$$
A(x)=\lim _{n \rightarrow \infty} \frac{1}{2^{\ell n}}\left(f\left(2^{\ell n+1} x\right)-8 f\left(2^{\ell n} x\right)\right)
$$

exists for all $x \in X$ and $A: X \rightarrow Y$ is a unique additive mapping satisfying

$$
\|f(2 x)-8 f(x)-A(x)\| \leq \frac{\left(|2 k+\ell|^{\lambda}+1\right)\left(9 k^{2}+4\right) \varepsilon\|x\|^{\lambda}}{\ell k^{2}\left(k^{2}-1\right)\left(1-2^{\lambda-1}\right)}
$$

for all $x \in X$, where $\lambda \ell<\ell$.

Proof. The proof is similar to the proof of Corollary 3.4 and the result follows from Theorem 4.2.

Theorem 4.5. Denote $N_{1}$ the fuzzy norm obtained as Corollary 3.4 on $R$. Let for all $x$ $\in X$, the functions $r \mapsto f(2 r x)-8 f(r x)$ (from $\left(R, N_{1}\right)$ into $\left.(Y, N)\right)$ and $r \mapsto \phi_{a}\left(\iota_{1} r x, \iota_{2} r y\right)$ from $\left(R, N_{1}\right)$ into $\left.\left(Z, N^{\prime}\right)\right)$ be fuzzy continuous, where $\iota_{1} \in\{1,2,(k+1),(k-1),(2 k+$ $1),(2 k-1)\}$ and $\iota_{2} \in\{1,2,3\}$. Then, for all $x \in X$, the function $r \mapsto A(r x)$ is fuzzy continuous and $A(r x)=r A(x)$ for all $r \in R$.

Proof. The proof is similar to the proof of Theorem 3.5 and the result follows from Theorem 4.2. 
Lemma 4.6. [22,24]. If an odd mapping $f: V_{1} \rightarrow V_{2}$ satisfies (1.5), then the mapping $h: V_{1} \rightarrow V_{2}$ defined by $h(x)=f(2 x)-2 f(x)$ is cubic.

Theorem 4.7. Let $\ell \in\{-1,1\}$ be fixed and let $\phi_{c}: X \times X \rightarrow Z$ be a mapping such that

$$
\varphi_{c}(2 x, 2 y)=\alpha \varphi_{c}(x, y)
$$

for all $x, y \in X$ and for some positive real number $\alpha$ with $\alpha \ell<8 \ell$. Suppose that an odd mapping $f: X \rightarrow Y$ satisfies the inequality

$$
N\left(D_{f}(x, y), t\right) \geq N^{\prime}\left(\varphi_{c}(x, y), t\right)
$$

for all $x, y \in X$ and all $t>0$. Then, the limit

$$
C(x)=N-\lim _{n \rightarrow \infty} \frac{1}{8^{\ell n}}\left(f\left(2^{\ell n+1} x\right)-2 f\left(2^{\ell n} x\right)\right)
$$

exists for all $x \in X$ and $C: X \rightarrow Y$ is a unique cubic mapping satisfying

$$
N(f(2 x)-2 f(x)-C(x), t) \geq M_{c}\left(x, \frac{\ell(8-\alpha)}{2} t\right)
$$

for all $x \in X$ and all $t>0$, where

$$
\begin{aligned}
M_{c}(x, t)= & \min \left\{N^{\prime}\left(\varphi_{c}(x, x), \frac{k^{2}\left(k^{2}-1\right)}{9 k^{2}+4} t\right), N^{\prime}\left(\varphi_{c}(2 x, x), \frac{k^{2}\left(k^{2}-1\right)}{9 k^{2}+4} t\right),\right. \\
& N^{\prime}\left(\varphi_{c}(x, 2 x), \frac{k^{2}\left(k^{2}-1\right)}{9 k^{2}+4} t\right), N^{\prime}\left(\varphi_{c}((k+1) x, x), \frac{k^{2}\left(k^{2}-1\right)}{9 k^{2}+4} t\right), \\
& \left.N^{\prime}\left(\varphi_{c}((k-1) x, x), \frac{k^{2}\left(k^{2}-1\right)}{9 k^{2}+4} t\right)\right), N^{\prime}\left(\varphi_{c}(2 x, 2 x), \frac{k^{2}\left(k^{2}-1\right)}{9 k^{2}+4} t\right), \\
& N^{\prime}\left(\varphi_{c}(x, 3 x), \frac{k^{2}\left(k^{2}-1\right)}{9 k^{2}+4} t\right), N^{\prime}\left(\varphi_{c}((2 k+1) x, x), \frac{k^{2}\left(k^{2}-1\right)}{9 k^{2}+4} t\right), \\
& \left.N^{\prime}\left(\varphi_{c}((2 k-1) x, x), \frac{k^{2}\left(k^{2}-1\right)}{9 k^{2}+4} t\right)\right\} .
\end{aligned}
$$

Proof. Case (1): $\ell=1$. Similar to the proof of Theorem 4.2, we have

$$
N(f(4 x)-10 f(2 x)+16 f(x), t) \geq M_{c}(x, t)
$$

for for all $x \in X$ and all $t>0$, where $M_{c}(x, t)$ is defined as in above. Letting $h: X \rightarrow$ $Y$ be a mapping defined by $h(x):=f(2 x)-2 f(x)$. Then, we conclude that

$$
N(h(2 x)-8 h(x), t) \geq M_{c}(x, t)
$$

for all $x \in X$ and all $t>0$. So

$$
N\left(\frac{h(2 x)}{8}-h(x), \frac{t}{8}\right) \geq M_{c}(x, t)
$$

for all $x \in X$ and all $t>0$. Then, by our assumption

$$
M_{c}(2 x, t)=M_{c}\left(x, \frac{t}{\alpha}\right)
$$


for all $x \in X$ and all $t>0$. Replacing $x$ by $2^{n} x$ in (4.34) and using (4.35), we obtain

$$
N\left(\frac{h\left(2^{n+1} x\right)}{8^{n+1}}-\frac{h\left(2^{n} x\right)}{8^{n}}, \frac{t}{8\left(8^{n}\right)}\right) \geq M_{c}\left(2^{n} x, t\right)=M_{c}\left(x, \frac{t}{\alpha^{n}}\right)
$$

for all $x \in X, t>0$ and $n \geq 0$. Replacing t by $\alpha^{n} t$ in (4.36), we see that

$$
N\left(\frac{h\left(2^{n+1} x\right)}{8^{n+1}}-\frac{h\left(2^{n} x\right)}{8^{n}}, \frac{t \alpha^{n}}{8\left(8^{n}\right)}\right) \geq M_{c}(x, t)
$$

for all $x \in X, t>0$ and $n>0$. It follows from $\frac{h\left(2^{n} x\right)}{8^{n}}-h(x)=\sum_{j=0}^{n-1}\left(\frac{h\left(2^{j+1} x\right)}{8^{j+1}}-\frac{h\left(2^{j} x\right)}{8^{j}}\right)$ and (4.37) that

$$
\begin{array}{r}
N\left(\frac{h\left(2^{n} x\right)}{8^{n}}-h(x), \sum_{j=0}^{n-1} \frac{\alpha^{j} t}{8(8)^{j}}\right) \geq \min \bigcup_{j=0}^{n-1}\left\{N\left(\frac{h\left(2^{j+1} x\right)}{8^{j+1}}-\frac{h\left(2^{j} x\right)}{8^{j}}, \frac{\alpha^{j} t}{8(8)^{j}}\right)\right\}( \\
\geq M_{c}(x, t)
\end{array}
$$

for all $x \in X, t>0$ and $n>0$. Replacing $x$ by $2^{m} x$ in (4.38), we observe that

$$
N\left(\frac{h\left(2^{n+m} x\right)}{8^{n+m}}-\frac{h\left(2^{m} x\right)}{8^{m}}, \sum_{j=0}^{n-1} \frac{\alpha^{j} t}{8(8)^{j+m}}\right) \geq M_{c}\left(2^{m} x, t\right)=M_{c}\left(x, \frac{t}{\alpha^{m}}\right)
$$

for all $x \in X$, all $t>0$ and all $m \geq 0, n>0$. So

$$
N\left(\frac{h\left(2^{n+m} x\right)}{8^{n+m}}-\frac{h\left(2^{m} x\right)}{8^{m}}, \sum_{j=m}^{n+m-1} \frac{\alpha^{j} t}{8(8)^{j}}\right) \geq M_{c}(x, t)
$$

for all $x \in X$, all $t>0$ and all $m \geq 0, n>0$. Hence

$$
N\left(\frac{h\left(2^{n+m} x\right)}{8^{n+m}}-\frac{h\left(2^{m} x\right)}{8^{m}}, t\right) \geq M_{c}\left(x, \frac{t}{\left.\sum_{j=m}^{n+m-1} \frac{\alpha^{j}}{8(8)^{j}}\right)}\right)
$$

for all $x \in X$, all $t>0$ and all $m \geq 0, n>0$. Since $0<\alpha<8$ and $\sum_{n=0}^{\infty}\left(\frac{\alpha}{8}\right)^{n}<\infty$, the Cauchy criterion for convergence and $\left(N_{5}\right)$ imply that $\left\{\frac{h\left(2^{n} x\right)}{8^{n}}\right\}$ is a Cauchy sequence in $(Y, N)$ to some point $C(x) \in Y$. So one can define the mapping $C: X \rightarrow Y$ by

$$
\left.C(x)=N-\lim _{n \rightarrow \infty} \frac{h\left(2^{n} x\right)}{8^{n}}\right)
$$

for all $x \in X$. Fix $x \in X$ and put $m=0$ in (4.39) to obtain

$$
N\left(\frac{h\left(2^{n} x\right)}{8^{n}}-h(x), t\right) \geq M_{c}\left(x, \frac{t}{\left.\sum_{j=0}^{n-1} \frac{\alpha^{j}}{8(8)^{j}}\right)}\right)
$$


for all $x \in X, t>0$ and $n>0$. From which we obtain

$$
\begin{aligned}
N(C(x)-h(x), t) & \geq \min \left\{N\left(C(x)-\frac{h\left(2^{n} x\right)}{8^{n}}, \frac{t}{2}\right), N\left(\frac{h\left(2^{n} x\right)}{8^{n}}-h(x), \frac{t}{2}\right)\right\} \\
& \geq M_{c}\left(x, \frac{t}{\left.\sum_{j=0}^{n-1} \frac{\alpha^{j}}{4\left(8^{j}\right)}\right)}\right)
\end{aligned}
$$

for $n$ large enough. Taking the limit as $n \rightarrow \infty$ in (4.41), we obtain

$$
N(C(x)-h(x), t) \geq M_{a}\left(x, \frac{t(8-\alpha)}{2}\right)
$$

for all $x \in X$ and all $t>0$. It follows from (4.36) and (4.40) that

$$
\begin{aligned}
N\left(\frac{C(2 x)}{8}-C(x), t\right) \geq & \min \left\{N\left(\frac{C(2 x)}{8}-\frac{h\left(2^{n+1} x\right)}{8^{n+1}}\right), \frac{t}{3}\right), N\left(\frac{h\left(2^{n} x\right)}{8^{n}}-C(x), \frac{t}{3}\right), \\
& \left.N\left(\frac{h\left(2^{n+1} x\right)}{8^{n+1}}-\frac{h\left(2^{n} x\right)}{8^{n}}\right), \frac{t}{3}\right)=M_{c}\left(x, \frac{8(8)^{n} t}{3 \alpha^{n}}\right)
\end{aligned}
$$

for all $x \in X$ and all $t>0$. Therefore,

$$
C(2 x)=8 C(x)
$$

for all $x \in X$. Replacing $x, y$ by $2^{n} x, 2^{n} y$ in (4.31), respectively, we obtain

$$
\begin{aligned}
N\left(\frac{1}{8^{n}} D_{h}\left(2^{n} x, 2^{n} y\right), t\right) & =N\left(D_{f}\left(2^{n+1} x, 2^{n+1} y\right)-2 D_{f}\left(2^{n} x, 2^{n} y\right), 8^{n} t\right) \\
& =\min \left\{N\left(D_{f}\left(2^{n+1} x, 2^{n+1} y\right), \frac{8^{n} t}{2}\right), N\left(D_{f}\left(2^{n} x, 2^{n} y\right), \frac{8^{n} t}{4}\right)\right\} \\
& \geq \min \left\{N^{\prime}\left(\varphi_{c}\left(2^{n+1} x, 2^{n+1} y\right), \frac{8^{n} t}{2}\right), N^{\prime}\left(\varphi_{c}\left(2^{n} x, 2^{n} y\right), \frac{8^{n} t}{4}\right)\right\} \\
& =\min \left\{N^{\prime}\left(\varphi_{c}(x, y), \frac{8^{n} t}{2 \alpha^{n+1}}\right), N^{\prime}\left(\varphi_{c}(x, y), \frac{8^{n} t}{4 \alpha^{n}}\right)\right\}
\end{aligned}
$$

which tends to 1 as $\mathrm{n} \rightarrow \infty$ for all $x, y \in X$ and all $t>0$. So we see that $C$, satisfies (1.5). Thus, by Lemma 4.6, the mapping $x \rightsquigarrow C(2 x)-2 C(x)$ is cubic. So (4.43) implies that the function $C$ is cubic. The rest of the proof is similar to the proof of Theorem 3.2 and we omit the details.

Remark 4.8. Let $0<\alpha<8$. Suppose that the function $t \mapsto N(f(2 x)-2 f(x)-C(x)$, .) from $(0, \infty)$ into $[0,1]$ is right continuous. Then, we obtain a better fuzzy approximation than(4.42).

Corollary 4.9. Let $X$ be a normed space and $Y$ be a Banach space. Let $\varepsilon, \lambda$ be nonnegative real numbers such that $\lambda \neq 3$. Suppose that an odd mapping $f: X \rightarrow Y$ satisfies the inequality (3.18) for all $x, y \in X$. Then, the limit

$$
C(x)=\lim _{n \rightarrow \infty} \frac{1}{8^{\ell n}}\left(f\left(2^{\ell n+1} x\right)-2 f\left(2^{\ell n} x\right)\right)
$$


exists for all $x \in X$ and $C: X \rightarrow Y$ is a unique cubic mapping satisfying

$$
\|f(2 x)-2 f(x)-C(x)\| \leq \frac{\left(|2 k+\ell|^{\lambda}+1\right)\left(9 k^{2}+4\right) \varepsilon\|x\|^{\lambda}}{\ell k^{2}\left(k^{2}-1\right)\left(4-2^{\lambda-1}\right)}
$$

for all $x \in X$, where $\lambda \ell<3 \ell$.

Theorem 4.10. Denote $N_{1}$ the fuzzy norm obtained as Corollary 3.4 on $R$. Let for all $x \in X$, the functions $r \mapsto f(2 r x)-2 f(r x)$ (from $\left(R, N_{1}\right)$ into $\left.(Y, N)\right)$ and $r \mapsto \phi_{q}\left(\iota_{1} r x, \iota_{2} r y\right)$ (from $\left(R, N_{1}\right)$ into $\left.\left(Z, N^{\prime}\right)\right)$ be fuzzy continuous, where $\iota_{1} \in\{1,2,(k+1),(k-1),(2 k+$ $1),(2 k-1)\}$ and $\iota_{2} \in\{1,2,3\}$. Then, for all $x \in X$, the function $r \mapsto C(r x)$ is fuzzy continuous and $C(r x)=r^{3} C(x)$ for all $r \in R$.

Proof. The proof is similar to the proof of Theorem 3.5 and the result follows from Theorem 4.7.

Theorem 4.11. Let $\phi: X \times X \rightarrow Z$ be a mapping such that

$$
\varphi(2 x, 2 y)=\alpha \varphi(x, y)
$$

for all $x, y \in X$ and for some positive real number $\alpha$. Suppose that an odd mapping $f$ $: X \rightarrow Y$ satisfies the inequality

$$
N\left(D_{f}(x, y), t\right) \geq N^{\prime}(\varphi(x, y), t)
$$

for all $x, y \in X$ and all $t>0$. Then, there exist a unique cubic mapping $C: X \rightarrow Y$ and a unique additive mappingA $: X \rightarrow Y$ such that

$$
N(f(x)-A(x)-C(x), t) \geq \begin{cases}\min \left\{M\left(x, \frac{3 t(2-\alpha)}{2}\right), M\left(x, \frac{3 t(8-\alpha)}{2}\right)\right\}, & 0<\alpha<2 \\ \min \left\{M\left(x, \frac{3 t(\alpha-2)}{2}\right), M\left(x, \frac{3 t(8-\alpha)}{2}\right)\right\}, & 2<\alpha<8 \\ \min \left\{M\left(x, \frac{3 t(\alpha-2)}{2}\right), M\left(x, \frac{3 t(\alpha-8)}{2}\right)\right\}, & \alpha>8\end{cases}
$$

for all $x \in X$ and all $t>0$, where

$$
\begin{aligned}
M(x, t)= & \min \left\{N^{\prime}\left(\varphi(x, x), \frac{k^{2}\left(k^{2}-1\right)}{9 k^{2}+4} t\right), N^{\prime}\left(\varphi(2 x, x), \frac{k^{2}\left(k^{2}-1\right)}{9 k^{2}+4} t\right),\right. \\
& N^{\prime}\left(\varphi(x, 2 x), \frac{k^{2}\left(k^{2}-1\right)}{9 k^{2}+4} t\right), N^{\prime}\left(\varphi((k+1) x, x), \frac{k^{2}\left(k^{2}-1\right)}{9 k^{2}+4} t\right), \\
& \left.N^{\prime}\left(\varphi((k-1) x, x), \frac{k^{2}\left(k^{2}-1\right)}{9 k^{2}+4} t\right)\right), N^{\prime}\left(\varphi(2 x, 2 x), \frac{k^{2}\left(k^{2}-1\right)}{9 k^{2}+4} t\right), \\
& N^{\prime}\left(\varphi(x, 3 x), \frac{k^{2}\left(k^{2}-1\right)}{9 k^{2}+4} t\right), N^{\prime}\left(\varphi((2 k+1) x, x), \frac{k^{2}\left(k^{2}-1\right)}{9 k^{2}+4} t\right), \\
& \left.N^{\prime}\left(\varphi((2 k-1) x, x), \frac{k^{2}\left(k^{2}-1\right)}{9 k^{2}+4} t\right)\right\} .
\end{aligned}
$$

Proof. Case (1): $0<\alpha<2$. By Theorems 4.2 and 4.7, there exist an additive mapping $A_{0}: X \rightarrow Y$ and a cubic mapping $C_{0}: X \rightarrow Y$ such that

$$
N\left(f(2 x)-8 f(x)-A_{0}(x), t\right) \geq M\left(x, \frac{t(2-\alpha)}{2}\right)
$$

and

$$
N\left(f(2 x)-2 f(x)-C_{0}(x), t\right) \geq M\left(x, \frac{t(8-\alpha)}{2}\right)
$$


for all $x \in X$ and all $t>0$. It follows from (4.48) and (4.49) that

$$
N\left(f(x)+\frac{1}{6} A_{0}(x)-\frac{1}{6} C_{0}(x), t\right) \geq \min \left\{M\left(x, \frac{3 t(2-\alpha)}{2}\right), M\left(x, \frac{3 t(8-\alpha)}{2}\right)\right\}
$$

for all $x \in X$ and all $t>0$. Letting $A(x)=-\frac{1}{6} A_{0}(x)$ and $C(x)=\frac{1}{6} C_{0}(x)$ in (4.50), we obtain

$$
N(f(x)-A(x)-C(x), t) \geq \min \left\{M\left(x, \frac{3 t(2-\alpha)}{2}\right), M\left(x, \frac{3 t(8-\alpha)}{2}\right)\right\}
$$

for all $x \in X$ and all $t>0$. To prove the uniqueness of $A$ and $C$, let $A^{\prime}, C^{\prime}: X \rightarrow Y$ be another additive and cubic mappings satisfying (4.51). Let $\bar{A}=A-A^{\prime}$ and $\bar{C}=C-C^{\prime}$. So

$$
\begin{aligned}
N(\bar{A}(x)+\bar{C}(x), t) & \geq \min \left\{N\left(f(x)-A(x)-C(x), \frac{t}{2}\right), N\left(f(x)-A^{\prime}(x)-C^{\prime}(x), \frac{t}{2}\right)\right\} \\
& \geq \min \left\{M\left(x, \frac{3 t(2-\alpha)}{4}\right), M\left(x, \frac{3 t(8-\alpha)}{4}\right)\right\}
\end{aligned}
$$

for all $x \in X$ and all $t>0$. Therefore, it follows from the last inequalities that

$$
\begin{aligned}
N\left(\bar{A}\left(2^{n} x\right)+\bar{C}\left(2^{n} x\right), 8^{n} t\right) & \geq \min \left\{M\left(2^{n} x, \frac{3\left(8^{n}\right) t(2-\alpha)}{4}\right), M\left(2^{n} x, \frac{3\left(8^{n}\right) t(8-\alpha)}{4}\right)\right\} \\
& =\min \left\{M\left(x, \frac{3\left(8^{n}\right) t(2-\alpha)}{4 \alpha^{n}}\right), M\left(x, \frac{3\left(8^{n}\right) t(8-\alpha)}{4 \alpha^{n}}\right)\right\}
\end{aligned}
$$

for all $x \in X$ and all $t>0$. So, $\lim _{n \rightarrow \infty} N\left(\frac{1}{8^{n}}\left(\bar{A}\left(2^{n} x\right)+\bar{C}\left(2^{n} x\right)\right), t\right)=1$, hence $\bar{C}=0$ and then $\bar{A}=0$. The rest of the proof, proceeds similarly to that in the previous case.

Remark 4.12. Let $0<\alpha<2$. Suppose that the function $t \mapsto N(f(x)-A(x)-C(x),$. from $(0, \infty)$ into $[0,1]$ is right continuous. Then, we obtain a better fuzzy approximation than (4.51).

Corollary 4.13. Let $X$ be a normed space and $Y$ be a Banach space. Let $\varepsilon, \lambda$ be nonnegative real numbers. Suppose that an odd mapping $f: X \rightarrow Y$ satisfies the inequality (3.18) for all $x, y \in X$. Then there exist a unique additive mapping $A: X \rightarrow Y$ and $a$ unique cubic mapping $C: X \rightarrow Y$ such that

$$
\begin{aligned}
& \|f(x)-A(x)-C(x)\| \\
& \leq\left(\begin{array}{l}
\frac{1}{6} \frac{\left(|2 k+\ell|^{\lambda}+1\right)\left(9 k^{2}+4\right) \varepsilon}{k^{2}\left(k^{2}-1\right)}\left(\frac{1}{\left(1-2^{\lambda-1}\right)}+\frac{1}{\left(4-2^{\lambda-1}\right)}\right)\|x\|^{\lambda}, \lambda<1 \\
\frac{\left(|2 k+\ell|^{\lambda}+1\right)\left(9 k^{2}+4\right) \varepsilon}{k^{2}\left(k^{2}-1\right)}\left(\frac{1}{\left(2^{\lambda-1}-1\right)}+\frac{1}{\left(4-2^{\lambda-1}\right)}\right)\|x\|^{\lambda}, 1<\lambda<3 \\
\frac{1}{6} \frac{\left(|2 k+\ell|^{\lambda}+1\right)\left(9 k^{2}+4\right) \varepsilon}{k^{2}\left(k^{2}-1\right)}\left(\frac{1}{\left(2^{\lambda-1}-1\right)}+\frac{1}{\left(2^{\lambda-1}-4\right)}\right)\|x\|^{\lambda}, \lambda>3
\end{array}\right.
\end{aligned}
$$

for all $x \in X$.

Proof. The result follows by Corollaries 4.4 and 4.9.

Theorem 4.14. Denote $N_{1}$ the fuzzy norm obtained as Corollary 3.4 on $R$. Let for all $x \in X$, the functions $r \mapsto f(r x)$ (from $\left(R, N_{1}\right)$ into $(Y, N)$ ) and $r \mapsto \phi\left(\iota_{1} r x, \iota_{2} r y\right)$ (from $(R$, $\left.N_{1}\right)$ into $\left.\left(Z, N^{\prime}\right)\right)$ be fuzzy continuous, where $\iota_{1} \in\{1,2,(k+1),(k-1),(2 k+1),(2 k-$ $1)\}$ and $\iota_{2} \in\{1,2,3\}$. Then, for all $x \in X$, the function $r \mapsto A(r x)+C(r x)$ is fuzzy continuous and $A(r x)+C(r x)=r A(x)+r^{3} C(x)$ for all $r \in R$.

Proof. The result follows by Theorems 4.5 and 4.10 . 


\section{Fuzzy stability of the functional equation (1.5)}

In this section, we prove the generalized Hyers-Ulam stability of a mixed cubic, quadratic, and additive functional equation (1.5) in fuzzy Banach spaces.

Theorem 5.1. Let $\phi: X \times X \rightarrow Z$ be a function which satisfies (3.1) and (4.45) for all $x, y \in X$ and for some positive real number $\alpha$. Suppose that a mapping $f: X \rightarrow Y$ satisfies the inequality

$$
N\left(D_{f}(x, y), t\right) \geq N^{\prime}(\varphi(x, y), t)
$$

for all $x, y \in X$ and all $t>0$. Furthermore, assume that $f(0)=0$ in (5.1) for the case $f$ is even. If $|k|=2$, then there exist a unique cubic mapping $C: X \rightarrow Y$, a unique quadratic mapping $Q: X \rightarrow Y$ and a unique additive mapping $A: X \rightarrow Y$ such that

$$
N(f(x)-C(x)-Q(x)-A(x), t) \geq\left\{\begin{array}{l}
\min \left\{\tilde{M}_{1}(x, t), \tilde{M}_{1}(-x, t)\right\}, 0<\alpha<2 \\
\min \left\{\tilde{M}_{2}(x, t), \tilde{M}_{2}(-x, t)\right\}, 2<\alpha<k^{2} \\
\min \left\{\tilde{M}_{3}(x, t), \tilde{M}_{3}(-x, t)\right\}, k^{2}<\alpha<8 \\
\min \left\{\tilde{M}_{4}(x, t), \tilde{M}_{4}(-x, t)\right\}, \alpha>8
\end{array}\right.
$$

for all $x \in X$ and all $t>0$, otherwise

$$
N(f(x)-C(x)-Q(x)-A(x), t) \geq\left\{\begin{array}{l}
\min \left\{\tilde{M}_{1}(x, t), \tilde{M}_{1}(-x, t)\right\}, 0<\alpha<2 \\
\min \left\{\tilde{M}_{2}(x, t), \tilde{M}_{2}(-x, t)\right\}, 2<\alpha<8 \\
\min \left\{\tilde{M}_{5}(x, t), \tilde{M}_{5}(-x, t)\right\}, 8<\alpha<k^{2} \\
\min \left\{\tilde{M}_{4}(x, t), \tilde{M}_{4}(-x, t)\right\}, \alpha>k^{2}
\end{array}\right.
$$

for all $x \in X$ and all $t>0$, where

$$
\begin{aligned}
& \tilde{M}_{1}(x, t)=\min \left\{N^{\prime}\left(\varphi(0, x), \frac{\left(k^{2}-\alpha\right)}{4} t\right), M\left(x, \frac{3 t(2-\alpha)}{4}\right), M\left(x, \frac{3 t(8-\alpha)}{4}\right\},\right. \\
& \tilde{M}_{2}(x, t)=\min \left\{N^{\prime}\left(\varphi(0, x), \frac{\left(k^{2}-\alpha\right)}{4} t\right), M\left(x, \frac{3 t(\alpha-2)}{4}\right), M\left(x, \frac{3 t(8-\alpha)}{4}\right\},\right. \\
& \tilde{M}_{3}(x, t)=\min \left\{N^{\prime}\left(\varphi(0, x), \frac{\left(\alpha-k^{2}\right)}{4} t\right), M\left(x, \frac{3 t(\alpha-2)}{4}\right), M\left(x, \frac{3 t(8-\alpha)}{4}\right\},\right. \\
& \tilde{M}_{4}(x, t)=\min \left\{N^{\prime}\left(\varphi(0, x), \frac{\left(\alpha-k^{2}\right)}{4} t\right), M\left(x, \frac{3 t(\alpha-2)}{4}\right), M\left(x, \frac{3 t(\alpha-8)}{4}\right\},\right. \\
& \tilde{M}_{5}(x, t)=\min \left\{N^{\prime}\left(\varphi(0, x), \frac{\left(k^{2}-\alpha\right)}{4} t\right), M\left(x, \frac{3 t(\alpha-2)}{4}\right), M\left(x, \frac{3 t(\alpha-8)}{4}\right\}\right.
\end{aligned}
$$

and

$$
\begin{aligned}
M(x, t)= & \min \left\{N^{\prime}\left(\varphi(x, x), \frac{k^{2}\left(k^{2}-1\right)}{9 k^{2}+4} t\right), N^{\prime}\left(\varphi(2 x, x), \frac{k^{2}\left(k^{2}-1\right)}{9 k^{2}+4} t\right),\right. \\
& N^{\prime}\left(\varphi(x, 2 x), \frac{k^{2}\left(k^{2}-1\right)}{9 k^{2}+4} t\right), N^{\prime}\left(\varphi((k+1) x, x), \frac{k^{2}\left(k^{2}-1\right)}{9 k^{2}+4} t\right), \\
& \left.N^{\prime}\left(\varphi((k-1) x, x), \frac{k^{2}\left(k^{2}-1\right)}{9 k^{2}+4} t\right)\right), N^{\prime}\left(\varphi(2 x, 2 x), \frac{k^{2}\left(k^{2}-1\right)}{9 k^{2}+4} t\right), \\
& N^{\prime}\left(\varphi(x, 3 x), \frac{k^{2}\left(k^{2}-1\right)}{9 k^{2}+4} t\right), N^{\prime}\left(\varphi((2 k+1) x, x), \frac{k^{2}\left(k^{2}-1\right)}{9 k^{2}+4} t\right), \\
& \left.N^{\prime}\left(\varphi((2 k-1) x, x), \frac{k^{2}\left(k^{2}-1\right)}{9 k^{2}+4} t\right)\right\} .
\end{aligned}
$$


Proof. Case (1): $0<\alpha<2$. Assume that $\phi: X \times X \rightarrow Z$ satisfies (1.6) for all $x, y \in X$. Let $f_{e}(x)=\frac{1}{2}(f(x)+f(-x))$ for all $x \in X$, then $f_{e}(0)=0, f_{e}(-x)=f_{e}(x)$, and

$$
N\left(D_{f_{e}}(x, y), t\right) \geq \min \left\{N^{\prime}(\varphi(x, y), t), N^{\prime}(\varphi(-x,-\gamma), t)\right\}
$$

for all $x, y \in X$ and all $t>0$. By Theorem 3.2 for all $x, y \in X$, there exist a unique quadratic mapping $Q: X \rightarrow Y$ such that

$$
N\left(f_{e}(x)-Q(x), t\right) \geq \min \left\{N^{\prime}\left(\varphi(0, x), \frac{\left(k^{2}-\alpha\right)}{2} t\right), N^{\prime}\left(\varphi(0,-x), \frac{\left(k^{2}-\alpha\right)}{2} t\right)\right\}
$$

for all $x \in X$ and all $t>0$. Now, if $\phi: X \times X \rightarrow Z$ satisfies (4.45) for all $x, y \in X$, and let $f_{o}(x)=\frac{1}{2}(f(x)-f(-x))$ for all $x \in X$, then

$$
N\left(D_{f_{o}}(x, y), t\right) \geq \min \left\{N^{\prime}(\varphi(x, y), t), N^{\prime}(\varphi(-x,-y), t)\right\}
$$

for all $x, y \in X$ and all $t>0$. By Theorem 4.11, it follows that there exist a unique cubic mapping $C: X \rightarrow Y$ and a unique additive mapping $A ; X \rightarrow Y$ such that

$$
\begin{aligned}
N\left(f_{o}(x)-C(x)-A(x), t\right) \geq & \min \left\{M\left(x, \frac{3 t(2-\alpha)}{2}\right), M\left(x, \frac{3 t(8-\alpha)}{2}\right)\right. \\
& \left., M\left(-x, \frac{3 t(2-\alpha)}{2}\right), M\left(-x, \frac{3 t(8-\alpha)}{2}\right)\right\}
\end{aligned}
$$

for all $x \in X$ and all $t>0$. It follows from (5.4) and (5.5) that

$$
\begin{aligned}
N(f(x)-C(x)-Q(x)-A(x), t) & \\
\geq & \min \left\{N^{\prime}\left(\varphi(0, x), \frac{\left(k^{2}-\alpha\right)}{4} t\right), M\left(x, \frac{3 t(2-\alpha)}{4}\right), M\left(x, \frac{3 t(8-\alpha)}{4}\right),\right. \\
& N^{\prime}\left(\varphi(0,-x), \frac{\left(k^{2}-\alpha\right)}{4} t\right), M\left(-x, \frac{3 t(2-\alpha)}{4}\right), M\left(-x, \frac{3 t(8-\alpha)}{4}\right\} \\
= & \min \left\{\tilde{M}_{1}(x, t), \tilde{M}_{1}(-x, t)\right\}
\end{aligned}
$$

The rest of the proof proceeds similarly to that in the previous case.

Remark 5.2. Let $0<\alpha<2$. Suppose that the function $t \mapsto N(f(x)-C(x)-Q(x)-A(x)$, .) from $(0, \infty)$ into $[0,1]$ is right continuous. Then, we obtain a better fuzzy approximation than (5.2) or (5.3).

Corollary 5.3. Let $X$ be a normed space and $Y$ be a Banach space. Let $\varepsilon, \lambda$ be nonnegative real numbers. Suppose that $f(0)=0$ in (3.18) for the case $f: X \rightarrow Y$ is even. Then, there exist a unique cubic mapping $C: X \rightarrow Y$, a unique quadratic mapping $Q$ : $X \rightarrow Y$ and a unique additive mapping $A: X \rightarrow Y$ such that

$$
\begin{aligned}
& \|f(x)-C(x)-Q(x)-A(x)\| \\
& \leq\left(\begin{array}{l}
\frac{1}{6} \frac{\left(|2 k+\ell|^{\lambda}+1\right)\left(9 k^{2}+4\right) \varepsilon}{k^{2}\left(k^{2}-1\right)}\left(\frac{1}{\left(1-2^{\lambda-1}\right)}+\frac{1}{\left(4-2^{\lambda-1}\right)}\right)\|x\|^{\lambda}+\frac{2 \varepsilon}{k^{2}-k^{\lambda}}\|x\|^{\lambda}, \lambda<1 \\
\quad \leq \frac{\left(|2 k+\ell|^{\lambda}+1\right)\left(9 k^{2}+4\right) \varepsilon}{k^{2}\left(k^{2}-1\right)}\left(\frac{1}{\left(2^{\lambda-1}-1\right)}+\frac{1}{\left(4-2^{\lambda-1}\right)}\right)\|x\|^{\lambda}+\frac{2 \varepsilon}{k^{2}-k^{\lambda}}\|x\|^{\lambda}, 1<\lambda<2 \\
\frac{1}{6} \frac{\left(|2 k+\ell|^{\lambda}+1\right)\left(9 k^{2}+4\right) \varepsilon}{k^{2}\left(k^{2}-1\right)}\left(\frac{1}{\left(2^{\lambda-1}-1\right)}+\frac{1}{\left(4-2^{\lambda-1}\right)}\right)\|x\|^{\lambda}+\frac{2 \varepsilon}{k^{\lambda}-k^{2}}\|x\|^{\lambda}, 2<\lambda<3 \\
\frac{1}{6} \frac{\left(|2 k+\ell|^{\lambda}+1\right)\left(9 k^{2}+4\right) \varepsilon}{k^{2}\left(k^{2}-1\right)}\left(\frac{1}{\left(2^{\lambda-1}-1\right)}+\frac{1}{\left(2^{\lambda-1}-4\right)}\right)\|x\|^{\lambda}+\frac{2 \varepsilon}{k^{\lambda}-k^{2}}\|x\|^{\lambda}, \lambda>3
\end{array}\right.
\end{aligned}
$$

for all $x \in X$.

Proof. The result follows by Corollaries 3.4 and 4.13. 
Theorem 5.4. Denote $N_{1}$ the fuzzy norm obtained as Corollary 3.4 on $R$. Let for all $x$ $\in X$, the functions $r \mapsto f(r x)$ (from $\left(R, N_{1}\right)$ into $\left.(Y, N)\right)$ and $r \mapsto \phi\left(\iota_{1} r x, \iota_{2} r y\right)$ (from $(R$, $\left.N_{1}\right)$ into $\left.\left(Z, N^{\prime}\right)\right)$ be fuzzy continuous, where $\iota_{1} \in\{0, \pm 1, \pm 2, \pm(k+1), \pm(k-1), \pm(2 k$ $+1), \pm(2 k-1)\}$ and $\iota_{2} \in\{ \pm 1, \pm 2, \pm 3\}$. Then, for all $x \in X$, the function $r \mapsto C(r x)+$ $Q(r x)+A(r x)$ is fuzzy continuous and $C(r x)+Q(r x)+A(r x)=r^{3} C(x)+r^{2} Q(x)+r A(x)$ for all $r \in R$.

Proof. The result follows by Theorems 3.5 and 4.14 .

\section{Acknowledgements}

The fourth author was supported by Basic Science Research Program through the National Research Foundation of Korea funded by the Ministry of Education, Science and Technology (NRF-2010-0021792).

\section{Author details}

${ }^{1}$ Department of Mathematics and Center of Excellence in Nonlinear Analysis and Applications (Cenaa), Semnan University, P.O. Box 35195-363, Semnan, Iran ${ }^{2}$ Department of Mathematics, University of Seoul, Seoul 130-743, Korea ${ }^{3}$ Department of Mathematics, Research Institute For Natural Sciences, Hanyang University, Seoul 133-791, Korea

\section{Authors' contributions}

All authors conceived of the study, participated in its design and coordination, drafted the manuscript, participated in the sequence alignment, and read and approved the final manuscript.

\section{Competing interests}

The authors declare that they have no competing interests.

\section{Received: 27 June 2011 Accepted: 26 October 2011 Published: 26 October 2011}

\section{References}

1. Ulam, SM: A Collection of the Mathematical Problems. Interscience Publishers, New York (1960)

2. Hyers, DH: On the stability of the linear functional equation. Proc Natl Acad Sci. 27, 222-224 (1941). doi:10.1073/ pnas. 27.4 .222

3. Aoki, T: On the stability of the linear transformation in Banach spaces. J Math Soc Japan. 2, 64-66 (1950). doi:10.2969/ jmsj/00210064

4. Rassias, ThM: On the stability of the linear mapping in Banach spaces. Proc Amer Math Soc. 72, 297-300 (1978). doi:10.1090/50002-9939-1978-0507327-1

5. Găvruta, P: A generalization of the Hyers-Ulam-Rassias stability of approximately additive mappings. J Math Anal Appl. 184, 431-436 (1994). doi:10.1006/jmaa.1994.1211

6. Aczel, J, Dhombres, J: Functional Equations in Several Variables. Cambridge University Press, Cambridge (1989)

7. Kannappan, Pl: Quadratic functional equation and inner product spaces. Res Math. 27, 368-372 (1995)

8. Skof, F: Propriet locali e approssimazione di operatori. Rend Sem Mat Fis Milano. 53, 113-129 (1983). doi:10.1007/ BF02924890

9. Adam, M: On the stability of some quadratic functional equations. J Nonlinear Sci Appl. 4(1):50-59 (2011)

10. Adam, M, Czerwik, S: On the stability of the quadratic functional equation in topological spaces. Banach J Math Anal. 1(2):245-251 (2007)

11. Czerwik, S: On the stability of the quadratic mapping in normed spaces. Abh Math Sem Univ Hamburg. 62, 59-64 (1992). doi:10.1007/BF02941618

12. Schin, SW, Ki, D, Chang, J, Kim, MJ: Random stability of quadratic functional equations: a fixed point approach. J Nonlinear Sci Appl. 4(1), 37-49 (2011)

13. Jun, KW, Kim, HM: The generalized Hyers-Ulam-Russias stability of a cubic functional equation. J Math Anal Appl. 274(2), 267-278 (2002)

14. Jung, S-M: Hyers-Ulam-Rassias Stability of Functional Equations in Mathematical Analysis. Hadronic Press, Palm Harbor (2001)

15. Jung, S-M: A fixed point approach to the stability of an equation of the square spiral. Banach J Math Anal. 1(2):148-153 (2007)

16. Khodaei, H, Rassias, TM: Approximately generalized additive functions in several variables. Int J Nonlinear Anal Appl. 1, 22-41 (2010)

17. Kim, CH: On the stability of mixed trigonometric functional equations. Banach J Math Anal. 1(2), 227-236 (2007)

18. Lee, Y-S, Chung, SY: Stability of a Jensen type functional equation. Banach J Math Anal. 1(1), 91-100 (2007)

19. Li, Y, Hua, L: Hyers-Ulam stability of a polynomial equation. Banach J Math Anal. 3(2), 86-90 (2009)

20. Park, C: Hyers-Ulam-Rassias stability of homomorphisms in quasi-Banach algebras. Banach J Math Anal. 1(1), 23-32 (2007)

21. Park, C, Rassias, TM: Isometric additive mappings in generalized quasi-Banach spaces. Banach J Math Anal. 2(1), 59-69 (2008)

22. Eshaghi Gordji, M, Khodaei, H: Solution and stability of generalized mixed type cubic, quadratic and additive functional equation in quasi-Banach spaces. Nonlinear Anal TMA. 71, 5629-5643 (2009). doi:10.1016/.na.2009.04.052

23. Najati, A, Moghimi, MB: Stability of a functional equation deriving from quadratic and additive function in quasi-Banach spaces. J Math Anal Appl. 337, 399-415 (2008). doi:10.1016/j.jmaa.2007.03.104 
24. Najati, A, Zamani Eskandani, G: Stability of a mixed additive and cubic functional equation in quasi-Banach spaces. J Math Anal Appl. 342, 1318-1331 (2008). doi:10.1016/j.jmaa.2007.12.039

25. Jun, KW, Kim, HM: Ulam stability problem for a mixed type of cubic and additive functional equation. Bull Belg Math Soc simon Stevin. 13, 271-285 (2006)

26. Kim, HM: On the stability problem for a mixed type of quartic and quadratic functional equation. J Math Anal Appl. 324, 358-372 (2006). doi:10.1016/j.jmaa.2005.11.053

27. Park, C: Fuzzy stability of a functional equation associated with inner product spaces. Fuzzy Sets Syst. 160, 1632-1642 (2009). doi:10.1016/j.fss.2008.11.027

28. Eshaghi Gordji, M: Stability of a functional equation deriving from quartic and additive functions. Bull Korean Math Soc 47(3), 491-502 (2010). doi:10.4134/BKMS.2010.47.3.491

29. Eshaghi Gordji, M: Stability of an additive-quadratic functional equation of two variables in F-spaces. J Nonlinear Sci Appl. 2(4), 251-259 (2009)

30. Eshaghi Gordji, M, Abbaszadeh, S, Park, C: On the stability of generalized mixed type quadratic and quartic functional equation in quasi-Banach spaces. J Ineq Appl 2009, 26 (2009). Article ID 153084

31. Eshaghi Gordji, M, Bavand-Savadkouhi, M, Rassias, JM, Zolfaghari, S: Solution and stability of a mixed type cubic and quartic functional equation in quasi-Banach spaces. Abs Appl Anal2009, 14. (Article ID 417473)

32. Eshaghi Gordji, M, Ebadian, A, Zolfaghari, S: Stability of a functional equation deriving from cubic and quartic functions. Abstr Appl Anal2008, 17. (Article ID 801904)

33. Eshaghi Gordji, M, Khodaei, H: On the Generalized Hyers-Ulam-Rassias stability of quadratic functional equations. Abs Appl Anal2009, 11. (Article ID 923476)

34. Forti, GL: An existence and stability theorem for a class of functional equations. Stochastica. 4, 23-30 (1980). doi:10.1080/17442508008833155

35. Forti, GL: Hyers-Ulam stability of functional equations in several variables. Aequationes Math. 50, 143-190 (1995). doi:10.1007/BF01831117

36. Găvruta, P, Găvruta, L: A new method for the generalized Hyers-Ulam-Rassias stability. Int J Nonlinear Anal Appl. 1(2):11-18 (2010)

37. Gordji, ME, Ghaemi, MB, Kaboli Gharetapeh, S, Shams, S, Ebadian, A: On the stability of J*-derivations. J Geom Phys. 60(3):454-459 (2010). doi:10.1016/j.geomphys.2009.11.004

38. Gordji, ME, Ghaemi, MB, Majani, H: Generalized Hyers-Ulam-Rassias theorem in menger probabilistic normed spaces. Discret Dyn Nat Soc. 11, 162371 (2010)

39. Gordji, ME, Ghaemi, MB, Majani, H, Park, C: Generalized Ulam-Hyers Stability of Jensen Functional Equation in erstnev PN spaces. J Ineq Appl. 14, 868193 (2010)

40. Gordji, ME, Kaboli-Gharetapeh, S, Park, C, Zolfaghri, S: Stability of an additive-cubic-quartic functional equation. Adv Differ Equ 2009, 20 (2009). Article ID 395693

41. Gordji, ME, Kaboli Gharetapeh, S, Rassias, JM, Zolfaghari, S: Solution and stability of a mixed type additive, quadratic and cubic functional equation. Adv Differ Equ2009, 17. (Article ID 826130)

42. Gordji, ME, Karimi, T, Kaboli Gharetapeh, S: Approximately n-Jordan homomorphisms on Banach algebras. J Ineq Appl 8 (2009). Article ID 870843

43. Gordji, ME, Khodaei, H, Khodabakhsh, R: General quartic-cubic-quadratic functional equation in non-Archimedean normed spaces. UPB Sci Bull Series A. 72(3), 69-84 (2010)

44. Bag, T, Samanta, SK: Finite dimensional fuzzy normed linear spaces. J Fuzzy Math. 11(3), 687-705 (2003)

45. Mirmostafaee, AK: A fixed point approach to almost quartic mappings in quasi fuzzy normed spaces. Fuzzy Sets Syst. 160, 1653-1662 (2009). doi:10.1016/j.fss.2009.01.011

46. Khodaei, H, Kamyar, M: Fuzzy approximately additive mappings. Int J Nonlinear Anal Appl. 1(2), 44-53 (2010)

47. Shakeri, S, Saadati, R, Park, C: Stability of the quadratic functional equation in non-Archimedean $\mathcal{L}$-fuzzy normed spaces. Int J Nonlinear Anal Appl. 1(2), 72-83 (2010)

48. Bag, T, Samanta, SK: Fuzzy bounded linear operators. Fuzzy Sets Syst. 151, 513-547 (2005). doi:10.1016/j.fss.2004.05.004

doi:10.1186/1029-242X-2011-95

Cite this article as: Gordji et al: Fuzzy Stability of Generalized Mixed Type Cubic, Quadratic, and Additive

Functional Equation. Journal of Inequalities and Applications 2011 2011:95.

\section{Submit your manuscript to a SpringerOpen ${ }^{\circ}$ journal and benefit from:}

- Convenient online submission

- Rigorous peer review

- Immediate publication on acceptance

- Open access: articles freely available online

- High visibility within the field

- Retaining the copyright to your article

Submit your next manuscript at $\gg$ springeropen.com 